\section{Time trends and predictors of mortality from ill-defined causes in old age: 9 year folllow-up of the Bambuí cohort study (Brazil)}

\author{
Tendências e fatores associados aos óbitos por \\ causas mal definidas em idosos: nove anos de \\ seguimento da coorte de Bambuí (Brasil)
}

\author{
1 Centro de Pesquisas René \\ Rachou, Fundação Oswaldo \\ Cruz, Belo Horizonte, Brasil. \\ 2 Núcleo de Estudos \\ em Saúde Pública e \\ Envelhecimento, Fundação \\ Oswaldo Cruz/Universidade \\ Federal de Minas Gerais, \\ Belo Horizonte, Brasil. \\ ${ }^{3}$ Faculdade de Saúde \\ Pública, Universidade de \\ São Paulo, São Paulo, Brasil. \\ 4 Departamento de \\ Estatística, Universidade \\ Federal de Minas Gerais, \\ Belo Horizonte, Brasil. \\ Correspondence \\ M. F. Lima-Costa \\ Laboratório de \\ Epidemiologia e Antropologia \\ Médica, Centro de Pesquisas \\ René Rachou, Fundação \\ Oswaldo Cruz. \\ Av. Augusto de Lima 1715, \\ sala 609, Belo Horizonte, $M G$ \\ 30190-002, Brasil. \\ lima-costa@cpqrr.fiocruz.br
}

\begin{abstract}
The study objective was to examine differentials in time trends and predictors of deaths assigned to symptoms, signs and ill-defined conditions in comparison with other ill-defined conditions (ill-defined cardiovascular diseases, cancer and injury) in a population-based cohort study. Of 1,606 baseline participants aged 60 years and over, 524 died during 9-year follow-up and were included in this study. Deaths coded to "symptoms" declined by 77\% in the period from 1997 1999 to 2003-2005. Deaths coded to other ill-defined conditions remained unchanged. The calendar period 2003-2005 ( $R R=0.25$; 95\%CI: 0.09$0.70)$ and in-hospital deaths (RR $=0.16$; 95\%CI: 0.08-0.34) were independently associated with "symptoms", but not with other ill-defined conditions. Baseline socio-demographic characteristics and chronic diseases were not predictors of these outcomes. International and national agencies have focused on the reduction of deaths assigned to "symptoms" to improve the registration of vital statistics, while other ill-defined conditions have received little attention. Our data provide evidence supporting the need to redress this situation.
\end{abstract}

Cause of Death; Mortality; Aged

\author{
Maria Fernanda Lima-Costa 1,2 \\ Divane Leite Matos 1,2 \\ Ruy Laurenti 3 \\ Maria Helena Prado de Mello-Jorge 3 \\ Cibele Comini Cesar 4
}

\section{Introduction}

Information from death certificates are the most widely available data for monitoring mortality patterns and for evaluating health programs over time 1. However, the usefulness of this data, generated from vital statistics registration systems, for meeting basic health policy purposes depends on its quality 1,2. Indicators of quality include completeness of registration, coverage, and the proportion of deaths coded to ill-defined conditions 1,2,3. For 105 World Health Organization (WHO) Member States, the median percentage of deaths assigned to ill defined conditions is $12 \%$. Deaths coded to these causes range from less than $5 \%$ in countries with high quality data to more than $40 \% 1$.

The proportion of deaths assigned to symptoms, signs and ill-defined conditions has been extensively used as a key indicator of the quality of coding of death certificates 1,4,5,6. However, other ill-defined conditions that do not represent useful underlying causes from a policy perspective have received little attention 1,2,3. These conditions consist of deaths from cardiovascular disease categories lacking diagnostic meaning, such as cardiac arrest and heart failure, cancer deaths coded to categories for secondary or unspecified sites, and injuries where the intent is not determined 1 .

To our knowledge, no population-based cohort study examined time trends and predictors 
of deaths assigned to ill defined conditions, and previous studies did not explore likely differentials of deaths coded to "symptoms" and to other ill-defined-conditions. These differentials might be especially relevant in the elderly, a population who often has several chronic diseases that concurrently lead to death, making it difficult to ascertain the cause of death 7,8. This information is an important element in improving strategies to strengthen vital statistics registration systems.

The Bambuí cohort is a population-based study of adverse health outcomes in the elderly. The subjects are well described, and the collected data include long-term mortality, and detailed information about socio-demographic characteristics, health status and health-related conditions. We used data from 9 years follow-up of the Bambuí cohort study to: (1) compare time trends of deaths assigned to "symptoms" to those of deaths assigned to other ill defined conditions; (2) examine predictors of these outcomes.

\section{Methods}

\section{Study area and population}

Bambuí city (15,000 inhabitants) is situated in the State of Minas Gerais, southeastern Brazil. The main economic activities in the study area are agriculture (particularly farming) and trade. The city has one general hospital and approximately one physician per 1,000 inhabitants 9 .

The Bambuí cohort study procedures have been described in detail elsewhere 9. Briefly, the baseline cohort population comprised all residents aged 60 and over on the 1st of January, 1997; 1,606 residents participated out of a total of 1,742 . Baseline data collection was performed from February to May, 1997. Cohort members undergo annual follow-ups, consisting of standardized interviews, selected examinations (blood tests, blood pressure measurements and electrocardiogram, among others), and verification of death certificates. All cohort members who died between 1997 and 2005 were eligible for the study. Participants signed an informed consent and authorized death certificate verification. The Bambuí cohort study was approved by the Ethics Board of the Oswaldo Cruz Foundation, Brazil.

\section{Mortality data source}

Deaths occurring up to December 31, 2005 were included in this analysis. Deaths were reported by next of kin during the annual follow-up interview and ascertained through the Brazilian Mortality Information System (SIM; http://www.datasus. gov.br), with the permission of the Ministry of Health; similar procedures were used to ascertain death for individuals who moved away from the study area (5.9\%). All individuals for whom death certificates were obtained were included in the present study.

Underlying cause of death was assigned according to the International Classification of Diseases, tenth revision (ICD-10) 10. The outcome variables in this study were deaths assigned to symptoms, signs, and ill-defined conditions (ICD10 codes R00-R99) and deaths assigned to other ill-defined conditions. Other ill-defined condition consisted of cardiovascular disease categories lacking diagnostic meaning (ICD-10 codes: I47.2, I49.0, I46, I50, I51.4, I51.5, I51.6, I51.9 and I70.9), cancer deaths coded to categories for secondary or unspecified sites (ICD-10 codes C76, $\mathrm{C} 80, \mathrm{C} 97)$, and deaths from injuries where the intent was not determined (ICD-10 codes: Y10-Y34 and Y87.2) 1 . The remaining causes of death were the reference group.

\section{Explanatory variables}

Explanatory variables in this study were year of death (calendar period), place of death (inside or outside hospitals), age at death, sex, number of complete years of schooling and family monthly income as a multiple of the Brazilian minimum wage (which was US\$120 per month in 1997). Baseline health and health related conditions consisted of those previously reported to be frequent competing causes of death 11 and/or those related to the leading underlying causes of death in the cohort members. These measures included: cognitive functioning and selected chronic diseases or conditions (hypertension, diabetes mellitus, coronary heart disease, intermittent claudication, stroke, heart failure and Trypanosoma cruzi infection).

Cognitive functioning was ascertained by using a Brazilian validated version of the MiniMental State Examination (MMSE), as previously reported 12 . Hypertension was defined by systolic blood pressure $(\mathrm{SBP}) \geq 140 \mathrm{mmHg}$ or diastolic blood pressure (DBP) $\geq 90 \mathrm{mmHg}$ or anti-hypertensive medication, and the measures were taken by using standard protocols 13 . Diabetes mellitus was defined as a fasting blood glucose level $\geq 126 \mathrm{mg} / \mathrm{dL}$ and/or current use of insulin or oral anti-diabetic drug treatment 14 . Coronary heart disease was ascertained by a medical history for myocardial infarction and by using the Rose's questionnaire for chest pain 15 . Intermittent claudication and stroke were defined by standard questionnaires 15,16. Heart failure was ascertained by a B-type natriuretic pep- 
tide level $\geq 100$ pgmL and electrocardiographic QRS duration $\geq 120 \mathrm{~ms} 17$. Infection with T. cruzi was assessed by seropositivity in three different methods run in parallel [hemaglutination (Biolab-Mérieux, France), and two enzyme-linked immunoabsorbent assays (Abbott, U.S.A. and Wierner, Argentina)].

\section{Statistical analysis}

The follow-up period was from the date of the baseline measurements until the date of death. Unadjusted analyses were based on Pearson's chi square and on one way ANOVA to examine the statistical significance of differences across frequencies and means, respectively. Principal component analysis was used to construct the individuals' health score, which was based on all health conditions included in this study. Adjusted relative risk ratios (RR) were estimated by multinomial logistic regression to assess the association between circumstances of death, baseline characteristics and death assigned to ill-defined conditions. The analysis was based on two models. First, we estimated the association between socio-demographic characteristics, health score, circumstance of death and deaths coded to illdefined conditions, having calendar period as an explanatory variable. Second, we estimated the above mentioned association stratified by calendar period. A separate analysis was implemented to examine the association between selected chronic diseases or conditions and deaths assigned to ill defined causes. The Stata statistical software version 10.0 (Stata Corp., College Station, U.S.A.) was used for the analyses.

\section{Results}

Over the 9 years of the study, 530 deaths were reported among cohort members. Death certificates were obtained for 524 individuals (98.9\%), who were included in the present analysis. Overall, $20.2 \%$ of deaths were assigned to ill-defined causes: $9.5 \%$ to "symptoms" and $10.4 \%$ to other ill-defined conditions $(8.8 \%$ were assigned to illdefined cardiovascular diseases, $1.5 \%$ to cancer coded to categories for secondary or unspecified sites and $0.4 \%$ to injury where the intent was not determined).

Of the total, 471 (88.9\%) of deaths were recorded in the vital statistics registration system. The proportion of deaths assigned to "symptoms" ( $p=0.602$ ) and to other ill-defined causes of death $(p=0.435)$ did not differ between death certificates recorded and not recorded in the SIM.

As shown in Figure 1, deaths assigned to "symptoms" decreased by over $77 \%$ during the study period: from $14.3 \%$ in $1997-1999$ to $11.4 \%$ in 2000-2002 and to $3.3 \%$ in 2003-2005. Deaths coded to other ill-defined conditions remained relatively unchanged (10.7\% in 1997-1999, 8.6\% in 2000-2002 and $12.7 \%$ in 2003-2005).

Table 1 shows the characteristics of the study participants by underlying cause of death. Among

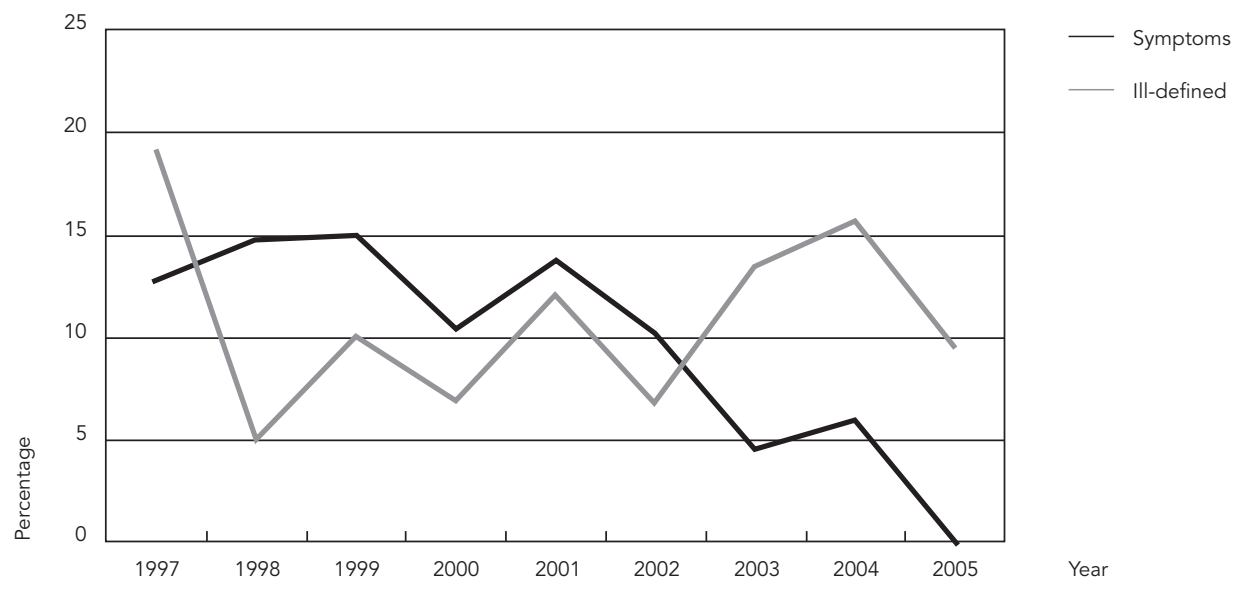


Characteristics of the study sample by underlying cause of death.

\begin{tabular}{|c|c|c|c|c|c|}
\hline Characteristics & All & $\begin{array}{l}\text { Symptoms, signs and } \\
\text { ill-defined conditions }\end{array}$ & $\begin{array}{l}\text { Other ill-defined } \\
\text { conditions * }\end{array}$ & $\begin{array}{l}\text { Other } \\
\text { causes }\end{array}$ & $\mathrm{p}$-value ** \\
\hline \multicolumn{6}{|l|}{ Calendar period of death } \\
\hline 1997-1999 [\%] & $168(32.1)$ & $24(48.0)$ & 18 (32.1) & $126(30.1)$ & 0.006 \\
\hline $2000-2002$ [\%] & $175(33.4)$ & $20(40.0)$ & $15(26.8)$ & $140(33.5)$ & \\
\hline $2003-2005$ [\%] & $181(34.5)$ & $6(12.0)$ & $23(41.1)$ & $152(36.4)$ & \\
\hline Death inside hospital [\%] & $337(64.3)$ & $15(30.0)$ & $34(60.7)$ & $288(68.9)$ & $<0.001$ \\
\hline Age at death [mean + SD] & $77.3 \pm 8.2$ & $76.7 \pm 9.5$ & $79.1 \pm 8.5$ & $77.1 \pm 8.0$ & 0.227 \\
\hline Female gender [\%] & $291(55.5)$ & $27(54.0)$ & $35(62.5)$ & $229(54.8)$ & 0.537 \\
\hline $\begin{array}{l}\text { Number of complete years of } \\
\text { schooling ( }<4 \text { years) [\%] }\end{array}$ & $380(72.8)$ & $37(74.0)$ & $38(67.9)$ & $305(73.3)$ & 0.676 \\
\hline $\begin{array}{l}\text { Family monthly income in the lowest } \\
\text { tercile (<2 Brazilian minimum wages) } \\
\star \star \star ~[\%]\end{array}$ & $188(36.1)$ & $19(38.0)$ & $21(38.2)$ & $148(35.6)$ & 0.979 \\
\hline $\begin{array}{l}\text { Cognitive functioning, mean MMSE } \\
\text { [score + SD] }\end{array}$ & $22.5 \pm 5.6$ & $22.5 \pm 5.0$ & $23.2 \pm 5.5$ & $22.4 \pm 5.7$ & 0.653 \\
\hline $\begin{array}{l}\text { Hypertension (SBP } \geq 140 \mathrm{mmHg} \text { or DBP } \\
\geq 90 \mathrm{mmHg} \text { or treatment) [\%] }\end{array}$ & $304(65.4)$ & $26(59.1)$ & $37(74.0)$ & $241(65.0)$ & 0.295 \\
\hline $\begin{array}{l}\text { Diabetes mellitus (blood glucose } \geq \\
126 \mathrm{mgdL} \text { or treatment) [\%] }\end{array}$ & $84(18.1)$ & $5(11.0)$ & $4(8.0)$ & $75(20.5)$ & 0.054 \\
\hline $\begin{array}{l}\text { Coronary heart disease (medical } \\
\text { diagnosis or questionnaire) [\%] }\end{array}$ & $62(13.5)$ & $5(11.4)$ & $9(18.4)$ & $48(13.2)$ & 0.549 \\
\hline $\begin{array}{l}\text { Intermittent claudication } \\
\text { (questionnaire) [\%] }\end{array}$ & $24(5.0)$ & $2(4.6)$ & $2(4.0)$ & $19(5.2)$ & 0.932 \\
\hline Stroke (questionnaire) [\%] & $27(5.8)$ & $4(9.1)$ & $2(4.0)$ & $21(5.7)$ & 0.554 \\
\hline $\begin{array}{l}\text { Heart failure [BNP and ECG QRS } \\
\text { duration) [\%] }\end{array}$ & $61(13.8)$ & $4(9.8)$ & $6(12.8)$ & $51(14.4)$ & 0.704 \\
\hline $\begin{array}{l}\text { Trypanosoma cruzi infection } \\
\text { (antibodies) [\%] }\end{array}$ & $212(46.5)$ & $21(47.7)$ & $23(46.0)$ & $169(46.4)$ & 0.984 \\
\hline Health score in the lowest tertile [\%] \# & $140(34.2)$ & $12(30.0)$ & $11(25.0)$ & $117(36.0)$ & 0.647 \\
\hline
\end{tabular}

BNP: B-type natriuretic peptide level $\geq 100$ pgmL; DBP: diastolic blood pressure; ECG QRS: electrocardiographic QRS duration $\geq 120 \mathrm{~ms}$; MMSE: Mini-Mental State Examination; SBP: systolic blood pressure.

* III-defined cardiovascular diseases, cancer coded as secondary or unspecified sites, and injuries where the intent is not determined;

** $\mathrm{p}$-value for differences across cause of death categories (Pearson's chi square for frequencies and oneway ANOVA for means);

*** Brazilian minimum wages (US\$ 120 in 1997).

\# The health score was estimated by principal component analysis based on the MMSE score, hypertension, diabetes mellitus, coronary heart disease intermittent claudication, stroke, heart failure and T. cruzi infection.

the 524 participants, the mean age at death was 77.3 years $(\mathrm{SD}=8.2)$, and women predominated (55.5\%). Most deaths (64.3\%) occurred in a hospital, and this proportion did not change significantly over the study period $(61.1 \%$ in $1997-1999$, $64 \%$ in $2000-2002$ and $67.4 \%$ in $2003-2005$; $p=$ $0.491)$. The results of the non-adjusted analysis showed that calendar period $(p=0.006)$ and hospital as place of death $(p<0.001)$ were the only characteristics found to be significantly associated with the underlying cause of death.

After adjustments for potential confounding variables, calendar period 2003-2005 $(\mathrm{RR}=$
0.25; 95\%CI: 0.09-0.70) and hospital as place of death $(\mathrm{OR}=0.16$; 95\%CI: 0.08-0.34) were found to be significantly and negatively associated with deaths assigned to "symptoms". Calendar period and place of death did not show significant associations with other ill-defined conditions in this analysis. Socio-demographic characteristics and the health score were not significantly associated with either "symptoms" or other ill-defined conditions (Table 2).

Most of the previous mentioned results remained unchanged in the analysis stratified by calendar period. Age at death, schooling, family 
Results of the multivariate analysis of the association between circumstances of death, baseline characteristics and deaths assigned to ill-defined conditions.

\begin{tabular}{|c|c|c|}
\hline Explanatory variables & $\begin{array}{c}\text { Symptoms, signs and ill-defined } \\
\text { conditions } \\
\text { RR }(95 \% \mathrm{Cl}) * \star\end{array}$ & $\begin{array}{l}\text { Other ill-defined } \\
\text { conditions * } \\
\text { RR }(95 \% \mathrm{Cl}) \text { ** }\end{array}$ \\
\hline \multicolumn{3}{|l|}{ Calendar period of death (vs. 1997-1999) } \\
\hline $2000-2002$ & $0.88(0.40-1.94)$ & $0.55(0.23-1.34)$ \\
\hline $2003-2005$ & 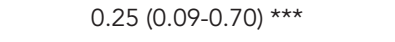 & $0.90(0.41-1.97)$ \\
\hline Death inside a hospital (vs. outside a hospital) & $0.16(0.08-0.34) * \star \star$ & $0.57(0.29-1.10)$ \\
\hline \multicolumn{3}{|l|}{ Age at death in years (vs. 60-69) } \\
\hline $70-79$ & $0.72(0.28-1.84)$ & $1.27(0.49-3.30)$ \\
\hline$\geq 80$ & $1.17(0.48-2.86)$ & $1.46(0.56-3.77)$ \\
\hline Female sex (vs. male) & $1.02(0.50-2.08)$ & $1.43(0.73-2.82)$ \\
\hline \multicolumn{3}{|l|}{ Number of complete years of schooling (vs. <4) } \\
\hline $4-7$ & $1.47(0.61-3.55)$ & $1.33(0.57-3.12)$ \\
\hline$\geq 8$ & $0.38(0.04-3.39)$ & $1.37(0.33-5.62)$ \\
\hline \multicolumn{3}{|c|}{ Family monthly income in Brazilian minimum wages (vs. <2) \# } \\
\hline $2-3.9$ & $0.82(0.36-1.89)$ & $1.09(0.49-2.39)$ \\
\hline$\geq 4$ & $0.85(0.33-2.17)$ & $1.24(0.53-2.91)$ \\
\hline \multicolumn{3}{|l|}{ Health score in terciles (vs. lowest) \#\# } \\
\hline 2nd & $1.14(0.46-2.81)$ & $1.81(0.76-4.30)$ \\
\hline Upper & $1.42(0.53-3.75)$ & $2.01(0.79-5.14)$ \\
\hline
\end{tabular}

RR: risk ratios; $95 \% \mathrm{Cl}$ : $95 \%$ confidence interval.

* III-defined cardiovascular diseases categories, cancer coded as secondary or unspecified sites, and injuries where the intent is not determined;

** RR $(95 \% \mathrm{Cl})$ estimated by multinomial logistic regression (defined causes of death are the reference group);

$\star \star \star$ p-value $<0.05$;

\# Brazilian minimum wages (US\$ 120 in 1997).

\#\# The health score was estimated by principal component analysis based on the Mini-Mental State Examination (MMSE) score, hypertension, diabetes

mellitus, coronary heart disease, intermittent claudication, stroke, heart failure and T. cruzi infection.

income, and health score continued to show no significant association with either "symptoms" or "ill-defined" conditions in both calendar periods. Hospital as place of death continued to have a strong effect on deaths assigned to "symptoms" in these periods, and this effect increases in 20032005. By contrast, a negative association between deaths inside hospitals and deaths assigned to other ill-defined conditions has emerged in the latter calendar period, as well as a positive association with female gender (Table 3 ).

None of the investigated chronic diseases or health conditions showed significant associations neither with deaths assigned to "symptoms" nor with deaths assigned to other ill-defined conditions (Table 4).

\section{Discussion}

This cohort study documents differences in time trends of deaths assigned to ill-defined conditions in a Brazilian population of older adults.
Deaths assigned to symptoms, signs and illdefined conditions had an impressive decline, while deaths assigned to other ill-defined conditions have remained relatively constant during the study period. These differences persisted after carefully controlling for hospital as place of death, demographic characteristics, indicators of social inequalities, and health conditions.

The reduction of deaths assigned to "symptoms" in the Bambuí cohort population is likely to be a consequence of improvements in coding procedures and/or on the quality of the information on death certificates and/or on more access to health services. These could be related: (1) to the ongoing cohort study, leading to an increase in the access to hospitalizations; (2) to more care in filling the death certificates and/or (3) to the improvement of the vital statistics system. The first hypothesis is unlikely because the percentage of deaths occurring in hospital remained stable during the study period. The second and third hypotheses are more plausible. One of the strategies implemented by the Brazilian Ministry 
Results of the multivariate analysis of the association between circumstances of death, baseline characteristics and deaths assigned to ill-defined conditions, stratified by calendar period.

\begin{tabular}{|c|c|c|c|c|}
\hline \multirow[t]{2}{*}{ Explanatory variables } & \multicolumn{2}{|c|}{$1997-1999$} & \multicolumn{2}{|c|}{ 2000-2005 } \\
\hline & $\begin{array}{l}\text { Symptoms, signs } \\
\text { and ill-defined } \\
\text { conditions } \\
\text { RR }(95 \% \mathrm{Cl}) * \star\end{array}$ & $\begin{array}{c}\text { Other ill- } \\
\text { defined } \\
\text { conditions * } \\
\text { RR }(95 \% \mathrm{Cl}) \text { ** }\end{array}$ & $\begin{array}{l}\text { Symptoms, signs } \\
\text { and ill-defined } \\
\text { conditions } \\
\text { RR }(95 \% \mathrm{Cl}) * *\end{array}$ & $\begin{array}{c}\text { Other ill- } \\
\text { defined } \\
\text { conditions * } \\
\text { RR }(95 \% \mathrm{Cl}) \text { ** }\end{array}$ \\
\hline Death inside a hospital (vs. outside a hospital) & 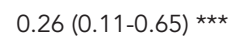 & $2.32(0.61-8.82)$ & 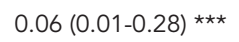 & $0.21(0.08-0.50) * \star \star x$ \\
\hline \multicolumn{5}{|l|}{ Age at death in years (vs. 60-69) } \\
\hline $70-79$ & $0.70(0.22-2.23)$ & $1.29(0.32-5.25)$ & $0.65(0.12-3.48)$ & $1.69(0.42-6.86)$ \\
\hline$\geq 80$ & $1.16(0.40-3.34)$ & $1.17(0.30-4.60)$ & $0.71(0.14-3.55)$ & $1.90(0.48-7.52)$ \\
\hline Female sex (vs male) & $1.00(0.40-3.34)$ & $0.49(0.15-1.55)$ & $1.10(0.31-3.89)$ & $3.54(1.28-9.73)$ * \\
\hline \multicolumn{5}{|l|}{ Number of complete years of schooling (vs. < 4) } \\
\hline $4-7$ & $1.31(0.42-4.12)$ & $1.00(0.25-4.16)$ & $1.75(0.41-7.48)$ & $1.43(0.47-4.41)$ \\
\hline$\geq 8$ & $0.56(0.05-5.87)$ & $1.01(0.08-12.2)$ & $0.37(0.01-7.65)$ & $1.72(0.29-10.37)$ \\
\hline \multicolumn{5}{|c|}{ Family monthly income in Brazilian minimum wages (vs. $<2$ )\# } \\
\hline $2-3.9$ & $1.07(0.40-2.89)$ & $1.90(0.48-7.46)$ & $0.38(0.07-1.91)$ & $0.74(0.25-2.16)$ \\
\hline$\geq 4$ & $1.06(0.31-3.57)$ & $1.78(0.39-8.11)$ & $0.52(0.10-2.68)$ & $0.94(0.32-2.77)$ \\
\hline \multicolumn{5}{|l|}{ Health score in terciles (vs. lowest) \#\# } \\
\hline 2nd & $1.37(0.45-4.14)$ & $2.38(0.63-8.91)$ & $1.00(0.18-5.49)$ & $1.48(0.45-4.90)$ \\
\hline Upper & $1.35(0.39-4.59)$ & $0.98(0.21-4.58)$ & $1.56(0.28-8.83)$ & $2.46(0.71-8.57)$ \\
\hline
\end{tabular}

RR: risk ratios; $95 \% \mathrm{Cl}$ : 95\% confidence interval.

* Other ill-defined conditions: ill-defined cardiovascular diseases categories, cancer coded as secondary or unspecified sites, and injuries where the intent is

not determined:

** RR $(95 \% \mathrm{Cl})$ estimated by multinomial logistic regression (defined causes of death are the reference group);

*** p-value <0.05;

\# Brazilian minimum wages (US\$ 120 in 1997).

\#\# The health score was estimated by principal component analysis based on the Mini-Mental State Examination (MMSE) score, hypertension, diabetes

mellitus, coronary heart disease, intermittent claudication, stroke, heart failure and T. cruzi infection.

of Health to improve the vital statistics registration system was the decentralization of some of the activities. Data cleaning and compilation is now done at the municipal, provincial and state levels, and an electronic data file is transferred to the national office every 3 months ${ }^{3}$. As part of these changes, since 1999 the death certificates of the study area have been coded at provincial level, under the supervision of the Health Secretariat of Minas Gerais, in the city of Divinopólis. Another change that happened during the study period was the implementation in 2002 of the local service of death certificate verification by the municipality. This service has been responsible for reviewing death certificates and for informing health professionals (Carvalho MLP; personal communication, 2009). The latter coincides with the period where a steeper decline in deaths assigned to "symptoms" in the study population was observed.

Diagnostic procedures are more available and death without medical assistance is unlikely in hospitals. Therefore, in these settings deaths coded to ill-defined causes are expected to be less frequent. Our results are in accordance with these observations. In the Bambuí cohort population, deaths inside hospitals were less likely to be coded to "symptoms", and this effect increased in the most recent triennium. Besides, the association between deaths occurring in hospital and deaths assigned to other ill-defined conditions has changed over time, indicating a recent influence of hospitalizations on deaths assigned to these codes.

In contrast to a previous study in the of State of Rio de Janeiro (Southeast Brazil) 5, we did not find evidence of an association between indicators of social inequality and deaths assigned to "symptoms"; there are no previous studies examining this influence on deaths assigned to other ill-defined conditions. However, it is important to note that our study was different from the previous one in several aspects. The Rio de Janeiro study was conducted in a large area with 
Results of the analysis of the association between selected baseline health conditions and deaths assigned to ill-defined conditions.

\begin{tabular}{|c|c|c|c|c|}
\hline \multirow[t]{3}{*}{ Explanatory variables } & \multicolumn{2}{|c|}{$\begin{array}{l}\text { Symptoms, signs and ill- } \\
\text { defined conditions }\end{array}$} & \multicolumn{2}{|c|}{ Other ill-defined conditions * } \\
\hline & $\begin{array}{l}\text { Age-sex } \\
\text { adjusted }\end{array}$ & Full-adjusted ** & $\begin{array}{l}\text { Age-sex } \\
\text { adjusted }\end{array}$ & Full-adjusted ** \\
\hline & $\mathrm{RR}(95 \% \mathrm{Cl}) * * *$ & $\mathrm{RR}(95 \% \mathrm{Cl}) * \star \star$ & $\mathrm{RR}(95 \% \mathrm{Cl}) * \star \star$ & $\operatorname{RR}(95 \% \mathrm{Cl}) * \star *$ \\
\hline Cognitive functioning (log MMSE score) & $1.78(0.30-1.42)$ & $1.36(0.46-3.96)$ & $1.54(0.57-4.14)$ & $1.41(0.48-4.12)$ \\
\hline $\begin{array}{l}\text { Hypertension ( } \mathrm{SBP} \geq 140 \mathrm{mmHg} \text { or } \mathrm{DBP} \geq 90 \mathrm{mmHg} \\
\text { or treatment) [vs. no] }\end{array}$ & $0.79(0.41-1.52)$ & $0.77(0.38-1.55)$ & $1.56(0.79-3.09)$ & $1.48(0.74-2.95)$ \\
\hline $\begin{array}{l}\text { Diabetes mellitus (blood glucose } \geq 126 \mathrm{mgdL} \text { or } \\
\text { treatment) [vs. no] }\end{array}$ & $0.51(0.19-1.36)$ & $0.53(0.18-1.46)$ & $0.35(0.12-1.01)$ & $0.35(0.12-1.01)$ \\
\hline $\begin{array}{l}\text { Coronary heart disease (medical diagnosis or } \\
\text { questionnaire) [vs. no] }\end{array}$ & $0.87(0.32-2.34)$ & $0.82(0.29-2.36)$ & $1.56(0.70-3.47)$ & $1.70(0.76-3.84)$ \\
\hline Intermittent claudication (questionnaire) [vs. no] & $0.83(0.18-3.74)$ & $0.60(0.12-3.04)$ & $0.84(0.18-3.79)$ & $1.00(0.27-3.67)$ \\
\hline Stroke (questionnaire) [vs. no] & $1.69(0.54-5.22)$ & $2.22(0.65-7.53)$ & $0.73(0.17-3.25)$ & $0.77(0.17-3.51)$ \\
\hline Heart failure (BNP and ECG QRS duration) [vs. no] & $0.54(0.22-1.89)$ & $0.56(0.18-1.76)$ & $0.85(0.34-2.10)$ & $0.87(0.34-2.21)$ \\
\hline T. cruzi infection (antibodies) [vs. no] & $1.08(0.57-2.05)$ & $1.25(0.61-2.54)$ & $0.91(0.50-1.68)$ & $1.01(0.52-1.94)$ \\
\hline
\end{tabular}

BNP: B-type natriuretic peptide level $\geq 100$ pgmL; DBP: diastolic blood pressure; ECG QRS: electrocardiographic QRS duration $\geq 120 \mathrm{~ms}$; MMSE: Mini-Mental State Examination; RR: risk ratios; $95 \% \mathrm{Cl}$ : 95\% confidence interval; SBP: systolic blood pressure.

* III-defined cardiovascular disease categories, cancer coded as secondary or unspecified sites, and injuries where the intent is not determined;

** Age at death, sex, schooling, family income, calendar period, and place of death;

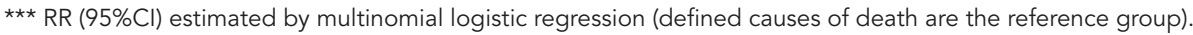

profound social inequalities, and it was based on information from death certificates, and included all age groups. Our study was conducted among an older population, in which socioeconomic differences were not prominent, and was based on socioeconomic information obtained through standard interviews at baseline. The results suggest that the influence of social inequalities on death certificates assigned to "symptoms" is influenced by local characteristics, and might vary among populations.

Co-morbidity at time of death is a well known predictor of inaccuracy in the cause of death $7,8,18$, and previous studies have shown that death certificates tend to be accurate when a person dies after a long, well-characterized disease 19,20. No cohort study, however, examined the influence of the baseline health status on long-term deaths assigned to ill-defined codes. We sought to examine this influence by assessing the effects of selected baseline health conditions on deaths assigned to "symptoms" and to other ill-defined conditions, and no evidence of association was found.

Some methodological aspects of this study merit comment. The Bambuí cohort was not planned for investigating the processes that led to changes of deaths assigned to ill-defined conditions, being this a limitation of the study.
Approximately $10 \%$ of the cohort members who died did not have their death certificates registered in the vital statistics registration system (the corresponding proportion for Brazil is 18\%) 3 . It is unlikely that this had affected our estimates because the proportion of deaths assigned to "symptoms" and to other ill-defined conditions did not differ between death certificates recorded and not recorded in this system. Finally, one of the advantages of the study was that it was community-based, which allowed for a meaningful estimate of deaths assigned to ill-defined conditions over a long period of time.

International and national agencies have focused on the reduction of deaths assigned to symptoms, signs and ill-defined conditions in order to improve the vital statistics registration systems, while other ill-defined conditions have received little attention 1 . Our data provide evidence supporting the need to redress this situation, by showing that: (1) the relative importance of other ill-defined conditions increases considerably in a scenario of decreased proportion of deaths assigned to "symptoms"; (2) the reduction of deaths assigned to "symptoms" was not followed by a reduction of deaths coded to illdefined conditions, indicating that factors that led to the latter had no effect on the former. 


\section{Resumo}

As tendências e os determinantes dos óbitos codificados como sinais, sintomas e afecções mal definidas ("sintomas") foram comparados a outras causas mal definidas (algumas doenças cardiovasculares, neoplasias e causas externas). De 1.606 participantes da coorte de base populacional de idosos de Bambuí, Minas Gerais, Brasil, 524 faleceram em nove anos de seguimento e foram incluídos no estudo. As mortes por "sintomas" diminuíram 77\% entre 1997-1999e 2003-2005. Os óbitos por outras causas mal definidas permaneceram inalterados. O período de 2003-2005 $(R R=0,25 ;$ IC95\%: 0,09-0,70) e os óbitos hospitalares $(R R=0,16$; IC95\%: 0,08-0,34) associaram-se independentemente com "sintomas", e não com as outras causas mal definidas. Características sócio-demográficas e doenças crônicas na linha de base não apresentaram associações com esses eventos. Estratégias para a redução dos óbitos por "sintomas" têm sido priorizadas por agências internacionais e nacionais, enquanto os óbitos por outras causas mal definidas têm recebido pouca atenção. Os resultados reforçam a necessidade de estratégias para mudar essa situação.

Causa de Morte; Mortalidade; Idoso

\section{Contributors}

M. F. Lima-Costa was responsible for the study concept and design, participated in the analysis and interpretation of data, and draft the manuscript. D. L. Matos contributed to data gathering and analysis, drafting of the manuscript and critical revision of the manuscript for important intellectual content. R. Laurenti and M. H. Mello-Jorge collaborated on drafting the manuscript and critical revision of the manuscript for important intellectual content. C. C. Cesar participated in the analysis and interpretation of data, drafting the manuscript, and critical revision of the manuscript for important intellectual content.

\section{Acknowledgments}

The authors gratefully acknowledge financial support for this project from the Health Surveillance Secretariat (SVS), Brazilian Ministry of Health, and from the Minas Gerais State Research Foundation (FAPEMIG), Brazil. M. F. Lima-Costa, D. L. Matos, R. Laurenti and M. H. P. Mello Jorge are fellows of the Brazilian Council for Scientific and Technological Development (CNPq).

\section{References}

1. Matters CD, Fat DM, Inoue M, Rao C, Lopez AD Counting the dead and what they died from: an assessment of the global status of cause of death data. Bull World Health Organ 2005; 83:171-7.

2. Mahapatra P, Shibuya K, Lopez AD, Coullare F, Notzan FC, Rao C, et al. Civil registration systems and vital statistics: successes and missed opportunities. Lancet 2007; 370:1653-63.

3. França E, Abreu DX, Rao C, Lopes AD. Evaluation of cause-of-death statistics for Brazil, 2002-2004 Int J Epidemiol 2008; 37:891-901.

4. Silvi J. On the estimation of mortality rates in countries of the Americas. Epidemiol Bull 2003; 24:1-5.
5. Costa MR, Marcopito LF. Mortalidade por causas mal definidas, Brasil, 1979-2002, e um modelo preditivo para idade. Cad Saúde Pública 2008; 24:1001-12.

6. Mello-Jorge MHP, Laurenti R, Lima-Costa MF, Gotlieb S, Chiavegatto Filho ADP. A mortalidade de idosos no Brasil: a questão das causas mal definidas. Epidemiol Serv Saúde 2008; 17:271-81.

7. Battle RM, Pathak D, Hule CG, Key CR, Vanatta PR, Hill RB, et al. Factors influencing discrepancies between premortem and postmortem diagnoses. JAMA 1987; 258:339-44. 
8. Lloyd-Jones DM, Martin DO, Larson MG, Levy D. Accuracy of death certificates for coding coronary heart disease as the cause of death. Ann Intern Med 1998; 129:1020-6.

9. Lima-Costa MFF, Uchoa E, Guerra HL, Firmo JOA, Vidigal PG, Barreto SM. The Bambuí Health and Ageing Study (BHAS): methodological approach and preliminary results of a population-based cohort study of the elderly in Brazil. Rev Saúde Pública 2000; 34:126-35.

10. World Health Organization. International statistical classification of diseases and related health problems, tenth revision. Geneva: World Health Organization; 1992.

11. Mackenbach JP, Kunst AE, Lautenbach H, Oei YB, Bijlsma F. Competing cause of death: a death certificate study. J Clin Epidemiol 1997; 50:1069-77.

12. Castro-Costa E, Fuzikawa C, Ferri C, Uchoa E, Firmo J, Lima-Costa MF, et al. Dimensions underlying the Mini-Mental Examination in a sample with low-education levels: the Bambui Health and Aging Study. Am J Geriatr Psychiatry 2009; 17:863-72.

13. Chobanian AV, Bakris GL, Black HR, Cushman WC, Green LA, Izzo Jr. JL, et al. The Seventh Report of the Joint National Committee on Prevention, Detection, Evaluation, and Treatment of High Blood Pressure: the JNC 7 report. JAMA 2003; 289: 2560-72.

14. Genuth S, Alberti KG, Bennett P, Buse J, Defronzo R, Kahn R, et al. Follow-up report on the diagnosis of diabetes mellitus. Diabetes Care 2003; 26:3160-7.
15. Rose GA. The diagnostic of ischaemic heart pain and intermittent claudication in field surveys. Bull World Health Organ 1962; 27:645-58.

16. Plan and operation of the Third National Health and Nutrition Examination Survey, 1988-94. Series 1: programs and collection procedures. Vital Health Stat 1 1994; (32):1-407.

17. Sakhuja R, Chen AA, Anwaruddin S, Baggish AL, Januzzi JL. Combined use of amino terminalpro-bain natriuretic pepitide levels and QRS duration to predict left ventricular systolic dysfunction in patients with dyspnea. Am J Cardiol 2005; 96:263-6.

18. D’Amico M, Agozzino E, Biagino A, Simonetti A, Marinelli P. Ill-defined and multiple causes on death certificates: a study of misclassification in mortality statistics. Eur J Epidemiol 1999; 15:141-8.

19. Kircher T, Anderson RE. Cause of death. Proper completion of the death certificate. JAMA 1987; 258:349-52.

20. Folsom AR, Gomez-Martin O, Gillium RF, Kottke TE, Lohman W, Jacobs Jr. DR. Out-of-hospital coronary death in an urban population: validation of death certificate diagnosis. The Minnesota Heart Survey. Am J Epidemiol 1987; 125:1012-8.

Submitted on 07/May/2009

Final version resubmitted on 27/Oct/2009

Approved on 18/Dec/2009 